\title{
Bullous Pemphigoid Associated with the Dipeptidyl Peptidase-4 Inhibitor Sitagliptin in a Patient with Liver Cirrhosis Complicated with Rapidly Progressive Hepatocellular Carcinoma
}

\author{
Masaru Harada ${ }^{1}$, Akitoshi Yoneda ${ }^{1}$, Sanehito Haruyama ${ }^{2}$, Kei Yabuki ${ }^{3}$, Yuichi Honma ${ }^{1}$, \\ Masaaki Hiura ${ }^{1}$, Michihiko Shibata ${ }^{1}$, Hidehiko Matsuoka ${ }^{1}$ and Yasuhiro Uchiwa ${ }^{4}$
}

\begin{abstract}
:
A 78-year-old man presented with cutaneous blisters of the limbs and abdominal distension. He had been treated for various diseases, including liver cirrhosis. He had begun receiving sitagliptin, a dipeptidyl peptidase-4 (DPP-4) inhibitor, for diabetes mellitus three years before the hospitalization. A skin biopsy demonstrated bullous pemphigoid. Ultrasonography (US) revealed multiple liver tumors, although he had been receiving regular US studies. We stopped sitagliptin and started insulin and corticosteroids. However, his renal dysfunction progressed, and he died 14 days after the hospitalization. We should therefore be careful of various complications, including bullous pemphigoid and progression of tumors, when using DPP-4 inhibitors.
\end{abstract}

Key words: bullous pemphigoid, dipeptidyl peptidase-4 inhibitor, hepatocellular carcinoma, progression, sitagliptin, nuclear factor E2-related factor 2 (Nrf2)

(Intern Med 56: 2471-2474, 2017)

(DOI: 10.2169/internalmedicine.8703-16)

\section{Introduction}

Dipeptidyl peptidase-4 (DPP-4, CD26) inhibitors (gliptins) are drugs used to treat type 2 diabetes mellitus. DPP-4 inhibitors delay the clearance of glucagon-like peptide-1 (GLP-1) and glucose-dependent insulinotropic polypeptide (GIP) $(1,2)$. DPP-4 inhibitors improve glucose-induced insulin secretion and decrease blood glucagon levels $(1,2)$. Therefore, DPP-4 inhibitors, such as sitagliptin, are widely used to treat patients with diabetes mellitus (3).

Bullous pemphigoid is an autoimmune subepidermal blistering disease (4). The target antigens of the autoimmune reaction of this disease are the hemidesmosomal proteins BP180 (BPAG2) and BP230 (BPAG1) (3). The precise etiology of this disease has not been clarified; however, it seems to be associated with certain medical conditions or medications in some patients $(5,6)$. Several recent studies have re- ported the association of DPP-4 inhibitors with bullous pemphigoid (7-15). Furthermore, DPP-4 is associated with both tumor prevention and tumor progression $(16,17)$.

We herein report a patient with bullous pemphigoid and rapidly progressive hepatocellular carcinoma (HCC) associated with sitagliptin treatment for diabetes mellitus.

\section{Case Report}

A 78-year-old man was referred to our hospital due to cutaneous blisters of the bilateral limbs and abdominal distension. He had been treated for liver cirrhosis (hepatitis C virus), dyslipidemia and hypertension for more than 10 years. He received ursodeoxycholic acid (300 mg/day), nicorandil (15 mg/day), pitavastatin calcium (1 mg/day) and aspirin (100 mg/day), and his condition had been satisfactory, although he had mild cognitive impairment, and his liver function tests were not completely stable. He had histories

\footnotetext{
${ }^{1}$ Third Department of Internal Medicine, School of Medicine, University of Occupational and Environmental Health, Japan, ${ }^{2}$ Department of Dermatology, School of Medicine, University of Occupational and Environmental Health, Japan, ${ }^{3}$ Department of Pathology and Oncology, School of Medicine, University of Occupational and Environmental Health, Japan and ${ }^{4}$ Uchiwa Clinic, Japan

Received: December 12, 2016; Accepted: January 31, 2017; Advance Publication by J-STAGE: August 21, 2017

Correspondence to Dr. Masaru Harada, msrharada@med.uoeh-u.ac.jp
} 
Table. Laboratory Findings.

\begin{tabular}{|c|c|c|c|c|c|}
\hline$<\mathrm{CBC}>$ & & $<$ Biochemistry $>$ & & $<$ Coagulation $>$ & \\
\hline WBC & $15,900 / \mu \mathrm{L}$ & $\mathrm{TP}$ & $6.5 \mathrm{~g} / \mathrm{dL}$ & PT & $88.4 \%$ \\
\hline Neutro & $86.9 \%$ & Alb & $2.1 \mathrm{~g} / \mathrm{dL}$ & INR & 1.03 \\
\hline Eosino & $0.1 \%$ & T-bil & $0.8 \mathrm{mg} / \mathrm{dL}$ & APTT & $33.9 \mathrm{sec}$ \\
\hline Lympho & $5.4 \%$ & AST & $100 \mathrm{U} / \mathrm{L}$ & Fib & $261 \mathrm{mg} / \mathrm{dL}$ \\
\hline Mono & $7.5 \%$ & ALT & $98 \mathrm{U} / \mathrm{L}$ & FDP & $22.3 \mu \mathrm{g} / \mathrm{mL}$ \\
\hline $\mathrm{RBC}$ & $437 \times 10^{4} / \mu \mathrm{L}$ & LDH & $486 \mathrm{U} / \mathrm{L}$ & & \\
\hline $\mathrm{Hb}$ & $14.0 \mathrm{~g} / \mathrm{dL}$ & ALP & $332 \mathrm{U} / \mathrm{L}$ & \multicolumn{2}{|l|}{$<$ Immunology $>$} \\
\hline $\mathrm{Ht}$ & $42.8 \%$ & $\gamma$-GTP & $48 \mathrm{U} / \mathrm{L}$ & CRP & $0.49 \mathrm{mg} / \mathrm{dL}$ \\
\hline \multirow[t]{2}{*}{ Plt } & $16.0 \times 10^{4} / \mu \mathrm{L}$ & BUN & $50 \mathrm{mg} / \mathrm{dL}$ & ANA & $<40$ \\
\hline & & Cre & $1.39 \mathrm{mg} / \mathrm{dL}$ & $\operatorname{IgG}$ & $2,609 \mathrm{mg} / \mathrm{dL}$ \\
\hline$<$ Urinalysis $>$ & & $\mathrm{Na}$ & $137 \mathrm{mmol} / \mathrm{L}$ & $\mathrm{BP} 180 \mathrm{Ab}$ & $5.5 \mathrm{U} / \mathrm{mL}$ \\
\hline Gravity & 1.029 & $\mathrm{~K}$ & $4.4 \mathrm{mmol} / \mathrm{L}$ & & \\
\hline Occult blood & $2+$ & $\mathrm{Cl}$ & $106 \mathrm{mmol} / \mathrm{L}$ & \multicolumn{2}{|l|}{$<$ Viral marker $>$} \\
\hline Protein & $3+$ & Ferritin & $137 \mathrm{ng} / \mathrm{mL}$ & HBsAg & $(-)$ \\
\hline Glucose & $4+$ & PG & $421 \mathrm{mg} / \mathrm{dL}$ & $\mathrm{HBc} \mathrm{Ab}$ & $(-)$ \\
\hline \multirow[t]{5}{*}{ Ketone } & $(-)$ & $\mathrm{HbA1c}$ & $9.4 \%$ & HCV RNA & $6.3 \log \mathrm{IU} / \mathrm{mL}$ \\
\hline & & HA & $1,750 \mathrm{ng} / \mathrm{mL}$ & & \\
\hline & & M2BPGi & $3.7 \mathrm{COI}$ & \multicolumn{2}{|c|}{$<$ Tumor marker> } \\
\hline & & Type IV collagen & $332 \mathrm{ng} / \mathrm{mL}$ & AFP & $356 \mathrm{ng} / \mathrm{mL}$ \\
\hline & & & & PIVKA-II & $564 \mathrm{mAU} / \mathrm{mL}$ \\
\hline
\end{tabular}

AFP: alfa fetoprotein, Alb: albumin, ALP: alkaline phosphatase, ALT: alanine aminotransferase, ANA: anti-nuclear antibody, APTT: activated partial thromboplastin time, AST: aspartate aminotransferase, BP180 Ab: antiBP180 antibody, BUN: blood urea nitrogen, CBC: complete blood count, COI: cut-off index, Cre: creatinine, CRP: C-reactive protein, Eosino: eosinophil, FDP: fibrinogen degradation products, Fib: fibrinogen, HA: hyaluronic acid, Hb: hemoglobin, HbAlc: hemoglobin Alc, HBcAb: anti-hepatitis B core antibody, HBsAg: hetatitis B surface antigen, HCV: hepatitis C virus, Ht: hematocrit, IgG: immunoglobulin G, INR: international normalized ratio, LDH: lactate dehydrogenase, Lympho: lymphocyte, M2BPGi: Mac 2 binding protein glycosylation isomer, Mono: monocyte, Neutro: neutrophil, PG: plasma glucose, PIVKA-II: protein induced by vitamin K absence or antagonists, Plt: platelet count, PT: prothrombin time, RBC: red blood cells, T-bil: total bilirubin, TP: total protein, WBC: white blood cells, $\gamma$-GTP: gamma glutamyltransferase

of cholelithiasis, brain infarction and cardiac infarction.

Sitagliptin $(25 \mathrm{mg} /$ day $)$, a DPP-4 inhibitor, had been started for diabetes mellitus 3 years before the hospitalization. Small blisters had appeared on his arms and legs, but they were very mild, and neither the patient nor his family had paid them any attention at the time. One month after the appearance of the blisters, he consulted his home doctor due to extended blisters and abdominal distension. At that time, renal dysfunction appeared, and his total protein level decreased and plasma glucose level and serum $\alpha$-fetoprotein (AFP) concentration increased. Therefore, his home doctor recommended him to visit our hospital.

A physical examination revealed a distended abdomen. Large blisters of the skin were found on the bilateral arms and legs. The laboratory findings at the first visit to our hospital included a low serum albumin concentration, renal dysfunction, high blood glucose concentration and proteinuria (urine protein/creatinine ratio $=0.78$ ) (Table). We immediately performed a skin biopsy, which showed subepidermal blister formation with moderate inflammatory infiltrates, including many eosinophils within the blister and in the perivascular and interstitial areas of the upper dermis (Fig. 1). Direct immunofluorescence for IgG (Fig. 2a), C3 (Fig. 2b) and $\mathrm{C} 4$ (data not shown) revealed linear deposition of these proteins at the subepidermal basement membrane zone. These skin biopsy findings suggested a diagnosis of bullous pemphigoid.

Anti-BP180 antibody was negative, and the concentrations of tumor markers for HCC, AFP and des-gamma-carboxy prothrombin [protein induced by vitamin $\mathrm{K}$ absence or antagonists (PIVKA-II)], were elevated (AFP, $356 \mathrm{ng} / \mathrm{mL}$ and PIVKA-II, $564 \mathrm{mAU} / \mathrm{mL}$ ). Therefore, we considered the existence of HCC. The AFP level at 6 months before the hospitalization had been $9 \mathrm{ng} / \mathrm{mL}$, and the PIVKA-II level at 3 months before the hospitalization had been $32 \mathrm{mAU} / \mathrm{mL}$. Ultrasonography (US) revealed multiple liver tumors (at least 4 tumors with a maximum size of $39 \mathrm{~mm}$ in diameter) and ascites (Fig. 3). He had been receiving regular US follow up. The most recent US examination performed at 53 days before the hospitalization had revealed a single highechoic nodule $18 \mathrm{~mm}$ in diameter. Because of the patient's age and various complications, the nodule had been kept under observation.

Sitagliptin was stopped, and insulin was used for the treatment of diabetes mellitus. We started corticosteroids (prednisolone $20 \mathrm{mg} / \mathrm{day}$ ) and diuretics. However, hypotension and renal dysfunction developed. The patient died 14 days after being hospitalized. 
a
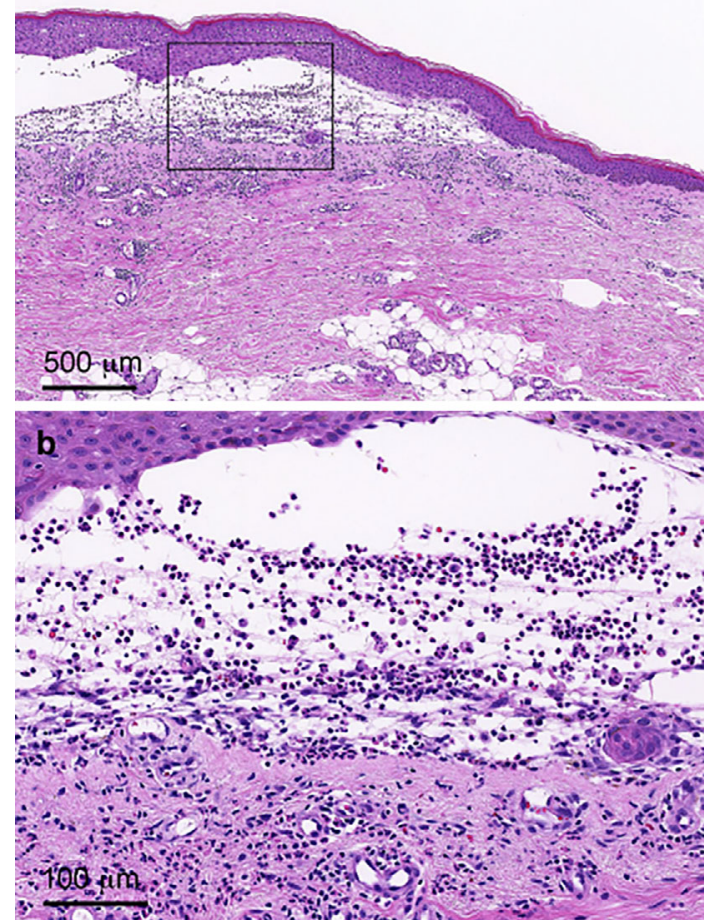

Figure 1. (a. b) Skin biopsy showed subepidermal blister formation with moderate inflammatory infiltrates, including many eosinophils, within the blister and in the perivascular and interstitial areas of the upper dermis (Hematoxylin and Eosin staining). (b) Higher magnification of figure (a).

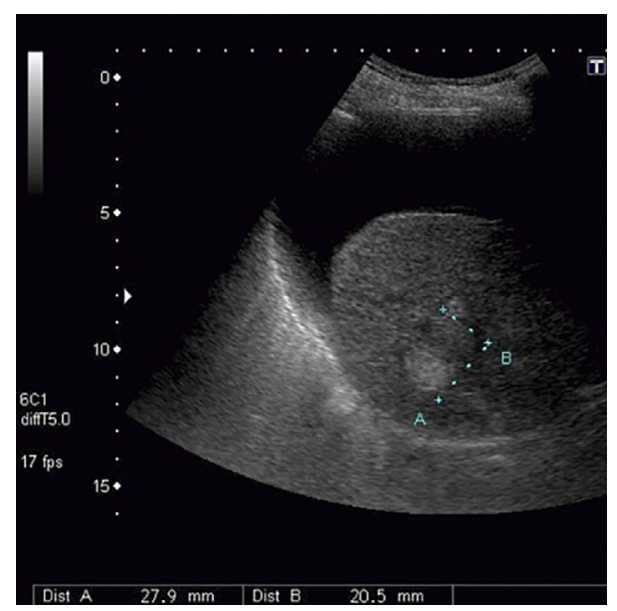

Figure 3. Ultrasonography revealed ascites and a liver tumor.

\section{Discussion}

Recent reports have described the association of DPP-4 inhibitors with bullous pemphigoid (7-15). In some of those reports, metformin had been used with DPP-4 inhibitors, but the present patient had never received metformin. The mechanisms underlying the association of DPP-4 inhibitors
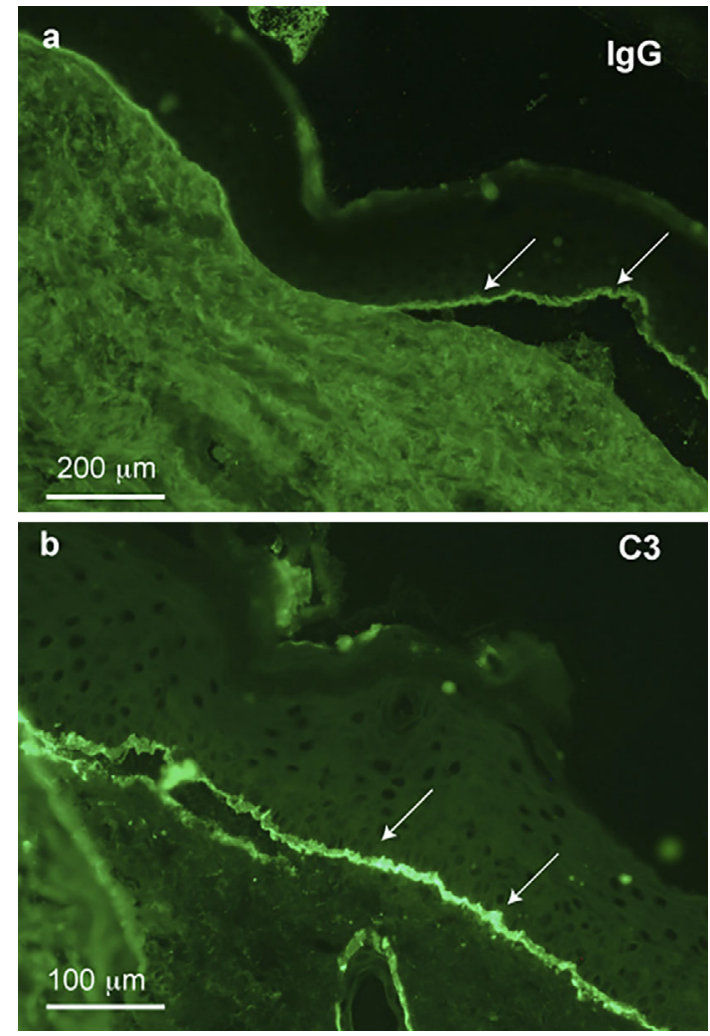

Figure 2. Direct immunofluorescence for IgG (a) and C3 (b) demonstrated the linear deposition of these proteins at the subepidermal basement membrane zone (arrows).

and bullous pemphigoid are unclear. DPP-4 is important for the immune system, and changes in the DPP-4 activity have been described in some autoimmune diseases, such as rheumatoid arthritis, systemic lupus erythematosus and inflammatory bowel disease $(2,10,18)$. Hemidesmosomal proteins are targets of autoimmune reactions of bullous pemphigoid (4). Therefore, immune disturbance may be a possible mechanism underlying this event. Although anti-BP180 antibody was negative in the present patient, $\operatorname{IgG}, \mathrm{C} 3$ and C4 depositions in the skin tissue were noted in his skin biopsy specimen (Fig. 2). Therefore, immune disturbance may be a possible mechanism of bullous pemphigoid.

DPP-4 distributes to many systemic tissues (19). Therefore, DPP-4 inhibitors can affect a number of physiological functions aside from glucose metabolism. Although the onset was rather late after the initiation of sitagliptin in the present patient, the association of sitagliptin with bullous pemphigoid cannot be excluded. Of course, the onset of bullous pemphigoid might have been spontaneous in the present patient. Recent study reported the association of cognitive impairment and bullous pemphigoid (8), and our patient had mild cognitive impairment. In addition, renal dysfunction and accumulation of ascites accompanied the onset of bullous pemphigoid in the present patient. These may be due to intravascular dehydration, renal hypoperfusion and hypoalbuminemia accompanied by proteinuria.

Multiple liver tumors were detected, and the levels of AFP (356 ng/mL) and PIVKA-II (564 mAU/mL) were ele- 
vated in our patient. The AFP level at 6 months before the hospitalization had been $9 \mathrm{ng} / \mathrm{mL}$, and the PIVKA-II level at 3 months before the hospitalization had been $32 \mathrm{mAU} / \mathrm{mL}$. These findings suggest that the HCC progressed rapidly in the present patient during the six months before visiting our hospital. DPP-4 is associated with nuclear factor E2-related factor 2 (Nrf2)-mediated antioxidant functions. Nrf2 is strongly associated with cancer and performs dual roles (protective and progressive) in cancer progression $(16,17)$. Recent reports have shown that the levels of DPP-4 inhibitors did not increase tumorigenesis but did increase the risk of progression of existing tumors $(20,21)$. DPP-4 inhibitors induce prolonged activation of $\operatorname{Nrf} 2(20,21)$. Therefore, they may reduce inflammation in hepatitis patients due to the antioxidant functions of $\mathrm{Nrf} 2$, which may in turn prevent tumorigenesis. However, once tumor cells appear, Nrf2 may induce tumor progression. Furthermore, DPP-4 induced apoptosis in human hepatoma cells and hepatoblastoma cells (22). Therefore, DPP-4 inhibitors may delay tumorigenesis during the first two years after initiation but may subsequently be associated with rapid disease progression after the appearance of HCC. Therefore, we should pay attention to the progression of preexisting tumors in patients suspected of having tumors, especially elderly patients with liver cirrhosis, when administering DPP-4 inhibitors.

We herein reported for the first time a patient with bullous pemphigoid and rapidly progressive HCC, likely associated with a DPP-4 inhibitor. DPP-4 inhibitors are widely used for type 2 diabetes mellitus and are usually safe, but they may have various effects on systemic functions. Therefore, we should be careful when using these drugs, especially in elderly patients with various serious complications, including cognitive impairment and liver cirrhosis.

The authors state that they have no Conflict of Interest (COI).

\section{References}

1. Muscelli E, Casolaro A, Gastaldelli A, et al. Mechanisms for the antihyperglycemic effect of sitagliptin in patients with type 2 diabetes. J Clin Endocrinol Metab 97: 2818-2826, 2012.

2. Itou M, Kawaguchi T, Taniguchi E, Sata M. Dipeptidyl peptidase4: a key player in chronic liver disease. World J Gastroenterol 19: 2298-2306, 2013.

3. Kubota A, Maeda H, Kanamori A, et al. Efficacy and safety of sitagliptin monotherapy and combination therapy in Japanese type 2 diabetes patients. J Diabetes Investig 3: 503-509, 2012.

4. Kasperkiewicz M, Zillikens D. The pathophysiology of bullous pemphigoid. Clin Rev Allergy Immunol 33: 67-77, 2007.

5. Bastuji-Garin S, Joly $\mathrm{P}$, Lemordant $\mathrm{P}$, et al. Risk factors for bullous pemphigoid in the elderly: a prospective case-control study. J Invest Dermatol 131: 637-643, 2011.

6. Stavropoulos PG, Soura E, Antoniou C. Drug-induced pemphigoid: a review of the literature. J Eur Acad Dermatol Venereol
28: 1133-1140, 2014.

7. Pasmatzi E, Monastirli A, Habeos J, Georgiou S, Tsambaos D. Dipeptidyl peptidase-4 inhibitors cause bullous pemphigoid in diabetic patients: report of two cases. Diabetes Care 34: e133, 2011.

8. Skandalis K, Spirova M, Gaitanis G, Tsartsarakis A, Bassukas ID. Drug-induced bullous pemphigoid in diabetes mellitus patients receiving dipeptidyl peptidase-IV inhibitors plus metformin. J Eur Acad Dermatol Venereol 26: 249-253, 2012.

9. Aouidad I, Fite C, Marinho E, Deschamps L, Crickx B, Descamps V. A case report of bullous pemphigoid induced by dipeptidyl peptidase-4 inhibitors. JAMA Dermatol 149: 243-245, 2013.

10. Attaway A, Mersfelder TL, Vaishnav S, Baker JK. Bullous pemphigoid associated with dipeptidyl peptidase IV inhibitors. A case report and review of literature. J Dermatol Case Rep 8: 24-28, 2014.

11. Béné J, Jacobsoone A, Coupe $P$, et al. Bullous pemphigoid induced by vildagliptin: a report of three cases. Fundam Clin Pharmacol 29: 112-114, 2015.

12. Mendonça FM, Martín-Gutierrez FJ, Ríos-Martín JJ, Camacho-Martinez F. Three cases of bullous pemphigoid associated with dipeptidyl peptidase-4 inhibitors - one due to linagliptin. Dermatology 232: 249-253, 2016.

13. Béné J, Moulis G, Bennani I, et al. Bullous pemphigoid and dipeptidyl peptidase IV inhibitors: a case-noncase study in the French Pharmacovigilance Database. Br J Dermatol 175: 296-301, 2016.

14. García M, Aranburu MA, Palacios-Zabalza I, Lertxundi U, Aguirre C. Dipeptidyl peptidase-IV inhibitors induced bullous pemphigoid: a case report and analysis of cases reported in the European pharmacovigilance database. J Clin Pharm Ther 41: 368370, 2016.

15. Sakai A, Shimomura Y, Ansai O, et al. Linagligiptin-associated bullous pemphigoid that was most likely caused by $\operatorname{IgG}$ autoantibodies against the mid portion of BP180. Br J Dermatol 176: 541543, 2017.

16. Jaramillo MC, Zhang DD. The emerging role of the Nrf2-Keap1 signaling pathway in cancer. Genes Dev 27: 2179-2191, 2013.

17. Menegon S, Columbano A, Giordano S. The dual roles of NRF2 in cancer. Trends Mol Med 22: 578-593, 2016.

18. Ohnuma K, Hosono O, Dang NH, Morimoto C. Dipeptidyl peptidase in autoimmune pathophysiology. Adv Clin Chem 53: 51-84, 2011.

19. Dinjens WN, ten Kate J, van der Linden EP, Wijnen JT, Khan PM, Bosman FT. Distribution of adenosine deaminase complexing protein (ADCP) in human tissues. J Histochem Cytochem 37: 1869-1875, 1989.

20. Wang H, Liu X, Long $M$, et al. NRF2 activation by antioxidant antidiabetic agents accelerates tumor metastasis. Sci Transl Med 8: 334ra51, 2016.

21. Tschöp MH, Stumvoll M, Ristow M. Opposing effects of antidiabetic interventions on malignant growth and metastasis. Cell Metab 23: 959-960, 2016.

22. Gaetaniello L, Fiore M, de Filippo S, Pozzi N, Tamasi S, Pignata C. Occupancy of dipeptidyl peptidase IV activates an associated tyrosine kinase and triggers an apoptotic signal in human hepatocarcinoma cells. Hepatology 27: 934-942, 1998.

The Internal Medicine is an Open Access article distributed under the Creative Commons Attribution-NonCommercial-NoDerivatives 4.0 International License. To view the details of this license, please visit (https://creativecommons.org/licenses/ by-nc-nd/4.0/).

(C) 2017 The Japanese Society of Internal Medicine

Intern Med 56: 2471-2474, 2017 